\title{
THE PARTICULARITIES OF THE CLARIFICATION PROCESS WITH BENTONITE OF WHITE WINE VINEGAR
}

\section{KEY WORDS:}

bentonite, white wine

vinegar, clarification process, physicochemical characteristics, filtration process

\author{
Alina Boistean ${ }^{1 *}$, Aurica Chirsanova ${ }^{1}$, Jorj Ciumac ${ }^{1}$, Boris Gaina ${ }^{2}$ \\ ${ }^{1}$ Technical University of Moldova, Chisinau, Republic of Moldova \\ ${ }^{2}$ Academy of Sciences of Moldova, Chisinau, Republic of Moldova
}

\begin{abstract}
In this study, the physicochemical properties of Italian and German bentonites were evaluated, including the physicochemical characteristics of white wine vinegar. Once established, the optimal clarification regime and its physical parameters were determined. After establishing the optimized sedimentation parameters, the influence of different doses of bentonite on the physicochemical and organoleptic characteristics of the analyzed vinegar was investigated. With this was determined the influence of the different contact periods of vinegar with bentonite, on the physicochemical parameters of clarified wine vinegar. Thus, for the Italian bentonite, the optimal conditions for the clarification process were: dose of bentonite $-2.03 \mathrm{~g} \cdot 25 \mathrm{~L}^{-1}$, time $-45 \mathrm{~min}$, temperature $20 \pm 1{ }^{\circ} \mathrm{C}$, stirring time $-60 \mathrm{~s}$, centrifugation time $-3 \mathrm{~min}$ and spin speed of $300 \mathrm{~min}^{-1}$. Moreover, when using the German bentonite, the optimal parameters were: bentonite dose $-1.96 \mathrm{~g} \cdot \mathrm{L}^{-1}$, contact time $-45 \mathrm{~min}$, temperature $-20 \pm 1{ }^{\circ} \mathrm{C}$, stirring time $-300 \mathrm{~s}$, centrifugation time $-3 \mathrm{~min}$ and spin speed of $300 \mathrm{~min}^{-1}$. Finally, the sensory analysis of wine vinegar was performed and it was established, from the data, which of the analyzed bentonites has properties that are more efficient on the clarification process.
\end{abstract}

\section{Introduction}

Wine vinegar is obtained from wine by acetous fermentation and in which the maximum level of volatile acids in the raw materials may be exceeded [1]. It is well known that the wine and vinegars, prepared from grape musts, wine, or cider, even if are correctly made, settled and filtered, may develop in time a cloudy appearance. These changes may significantly reduce the market value to consumers which are requiring intense clarity for bottled liquids, as a proof of quality [2].

For these purpose the vinegar is treated with bentonite, and its removal is accomplished by adsorption or precipitation based on electric charge counterbalancing of the molecules [3]. Adsorption was shown to be independent of temperature, but varied slightly with protein content, $\mathrm{pH}$ and ethanol content [4].

One of the perceived disadvantages of bentonite fining is that it is thought to reduce flavor and aroma of wines. This perception is not supported by strong evidence in the normal operational range of bentonite additions by winemakers. Sensory evaluation of wines treated with bentonite showed no significant differences between the control and the fined samples [5].

\section{Materials and methods}

\subsection{Materials}

In this work, white wine vinegar was used, the raw material was taken from the wine factory in the city of Ialoveni. White wine vinegar was obtained as part of a scientific research that took place in the faculty of Food Technology, Technical University of Moldova. The obtained wine vinegar corresponds to the quality indicators stipulated in the Government Decision of the Republic of Moldova no. 1403, Art. III, to be accepted and allowed for consumption in food [6]. To clarify the white wine vinegar two types of bentonite were used: the first producer - Italy (Enartis, Francesco Bergaglio, Italia), natural mineral, $\mathrm{Ca}$ - bentonite (calcium bentonite); Germany (Erbslöh, Geisenheim, Germany) is the second largest producer of natural mineral, $\mathrm{Na}-\mathrm{Ca}$ bentonite.

\subsection{Methods}

2.2.1. Analysis of physicochemical indices of bentonites

The beginning of the study was carried out to determine the physicochemical parameters of bentonites. The following param- eters were defined: the density, the porosity [7], the dry matter [8], $\mathrm{pH}$ [9], the swelling index [10], the ash content [11].

\subsubsection{Analysis of the physicochemical indices of vinegar}

The optic density was determined using the Spectrophotometer LLG-uniSPEC2 [12]. The dry matter of the wine vinegar samples was determined according to the standardized methods [13]. The total acidity content, expressed in grams of acetic acid per liter of the sample, was determined by titration. In order to quantify the contribution of acidity when the solid is in contact with the solution was determined and the vinegar $\mathrm{pH}$ value using the device Hanna. The ash content can serve to identify certain types of fraud, such as the addition of water or an aqueous solution of acetic acid. The ashes of vinegar were determined through incineration of the vinegar extract conducted between $500{ }^{\circ} \mathrm{C}$ and $550{ }^{\circ} \mathrm{C}$ until the complete combustion of carbon [14]. Considering that the vinegar is a wine byproduct, the residual alcohol content, expressed as a percentage (v/v) was appreciated. Sensorial appreciation was conducted against a control sample [15].

\section{Results and discussion}

The study started with the determination of the raw material parameters, which was subsequently used for clarification. The obtained results, for the bentonites are presented in Table 1.

The results on the physicochemical composition of wine vinegar are shown in Table 2.

\subsection{Determining the optimal dose of bentonite}

The influence of the Italy and German bentonite dose, which ranged from $0.45 \mathrm{~g} \cdot \mathrm{L}^{-1}$ to $2.93 \mathrm{~g} \cdot \mathrm{L}^{-1}$, was investigated on the white wine vinegar clearing process. The optimal dose of German bentonite was established based on Figure 1, and its value is equal to $1.96 \mathrm{~g} \cdot \mathrm{L}^{-1}$, and the optimal dose of Italian bentonite its value is $2.03 \mathrm{~g} \cdot \mathrm{L}^{-1}$.

The experimental data allow us to state that the clearing effect of white wine vinegar for both types of bentonite is observed at a higher dose $0.5 \mathrm{~g} \cdot \mathrm{L}^{-1}$. An essential increase in the clearing effect is determined at a dose of $2 \mathrm{~g} \cdot \mathrm{L}^{-1}$. Subsequent increase in the dose of bentonite has a significant influence on the vinegar clearing process. 
Physicochemical parameters of bentonites

\begin{tabular}{cccccc}
\hline Indices & Density, $\mathbf{g} \cdot \mathbf{c m}^{-3}$ & Porosity, \% & Ash content, \% & Swelling index, \% & pH \\
\hline Italian bentonite & $1.2 \pm 0.2$ & $0.35 \pm 0.01$ & $14.55 \pm 0.1$ & $39.20 \pm 0.1$ & $8.79 \pm 0.04$ \\
\hline German bentonite & $1.31 \pm 0.5$ & $0.35 \pm 0.02$ & $17.50 \pm 0.2$ & $31.19 \pm 0.2$ & $11.16 \pm 0.08$
\end{tabular}

Physicochemical parameters of white wine vinegar

Table 2

\begin{tabular}{|c|c|c|c|c|c|c|}
\hline Indices & Acidity \% & pH & Density $\mathbf{g} \cdot \mathbf{c m}^{-3}$ & Dry matter, \% & Ash content, \% & $\begin{array}{c}\text { Residual alcohol } \\
\% \text { alc. }\end{array}$ \\
\hline Vinegar & $4.95 \pm 0.04$ & $3.11 \pm 0.2$ & $1.013 \pm 0.01$ & $16.55 \pm 0.75$ & $5.37 \pm 0.08$ & $> \pm 3 \%$ \\
\hline
\end{tabular}

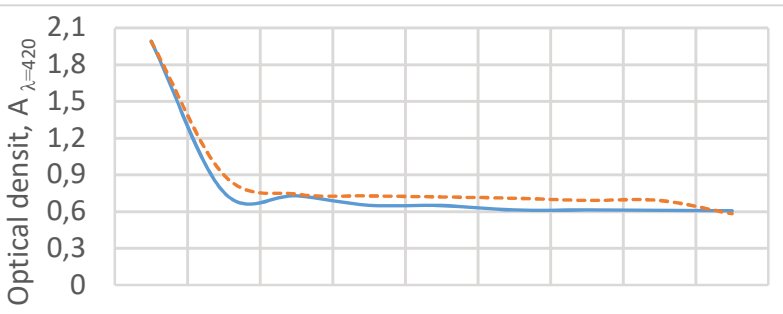

$\begin{array}{lllllllll}0 & 0,50 & 0,95 & 1,25 & 1,60 & 1,96 & 2,03 & 2,50 & 3,00\end{array}$ Quantity of bentonite, $\mathrm{g} \cdot \mathrm{L}^{-1}$

Italy bentonite -.---.-. Germany bentonite

Figure 1. Establishing the optimal dose of German and Italian bentonite

\subsection{The influence of time on the white wine vinegar clearing process}

Time is a parameter that influences the clearing process. In order to determine the optimum contact time of the Italian and Germany bentonite suspension with white wine vinegar, 6 samples were performed, in which the optimal amount of bentonite was used and the experiment was carried out in an interval from 1 to $48 \mathrm{hr}$ Figure 2. Analyzing the results of the optical density of vinegar clarification with Italian bentonite in time dependence it observed that this value decreases instantly after one hour of contact. Based on the optical density values of white wine vinegar clarification with German bentonite in time dependence it observed that this value decreases instantly after one hour of contact. However, it observed that between $0-3 \mathrm{hr}$ there is a very large instability and variation of the optical density values. This is due to the gelling structure of the bentonite suspension, because the conglomerations formed did not reduce the contact surface of the bentonite with the vinegar, which led to the obtaining of erroneous data. To avoid this instability, it was necessary to carry out a more detailed analysis of this time interval and to make a homogeneous mixing. For this reason, it was necessary to carry out a more detailed analysis of this time interval. Thus, the analysis of three vinegar samples with Italian and Germany bentonite that were place between $0.45-1.30 \mathrm{hr}$ was perform Figure 3. Based on the data presented in Figure 3, it noted that the optimal contact time of the Italy and Germany bentonite suspension with wine vinegar is $0.45 \mathrm{hr}$. This time was selected despite the variation of

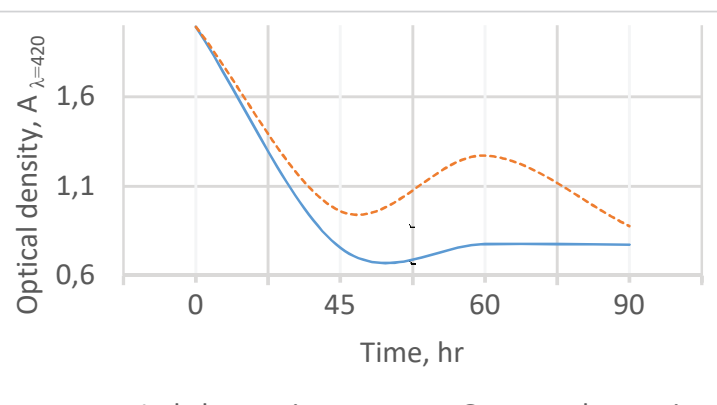

- Italy bentonite -------- Germany bentonite

Figure 3. Establishing the optimum time for wine vinegar clarification

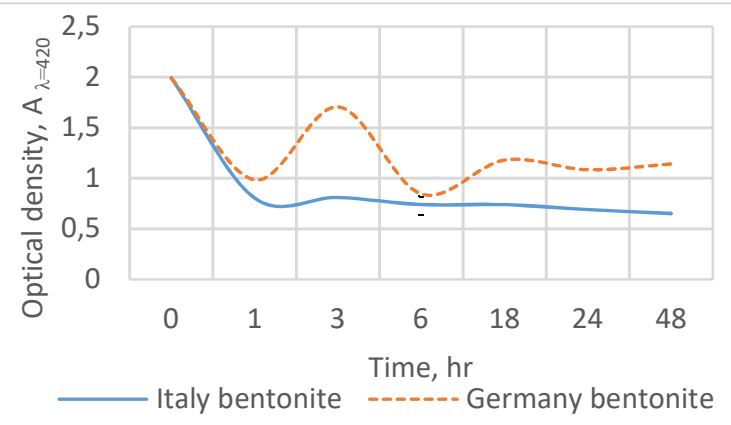

Figure 2. Dependence of the optical density on clarification time

the optical density values, because the capacity of conglomeration formation of Germany bentonite was taken into account, which causes erroneous data to be obtained.

\subsection{The influence of temperature on the vinegar clearing process}

Temperature is another important factor in the clearing process. Because opting for a well-clarified preparation, experiments were carried out to determine the value of the optimum temperature. The determination of the optimal wine vinegar clarification temperature was performed by placing at three different temperatures (refrigeration $-10 \pm 1{ }^{\circ} \mathrm{C}$, at room temperature $-20 \pm 1{ }^{\circ} \mathrm{C}$ and steam bath $-35 \pm 1{ }^{\circ} \mathrm{C}$ ) three vinegar samples in which the optimum amount of bentonite was added. Figure 4 show the optical density values for both types of bentonite depending on the temperature at which the white wine vinegar clearing process took place. The results of the experiments carried out show that the temperature variation does not greatly influence the clearing process. From the obtained data it was established that the optimum temperature for both types of bentonite is $20 \pm 1{ }^{\circ} \mathrm{C}$, because the lowest value of the optical density was obtained.

\subsection{The influence of the hydrodynamic contact regime of white wine vinegar with bentonite suspension}

The effect of the clarification process with the bentonite suspension depends largely on the intensity of mixing with the white wine vinegar. The influence of the active contact on the adsorption

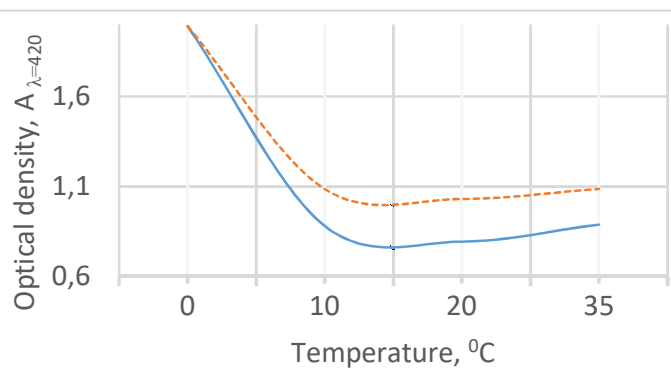

Italy bentonite -------- Germany bentonite

Figure 4. Dependence of optical density on temperature 


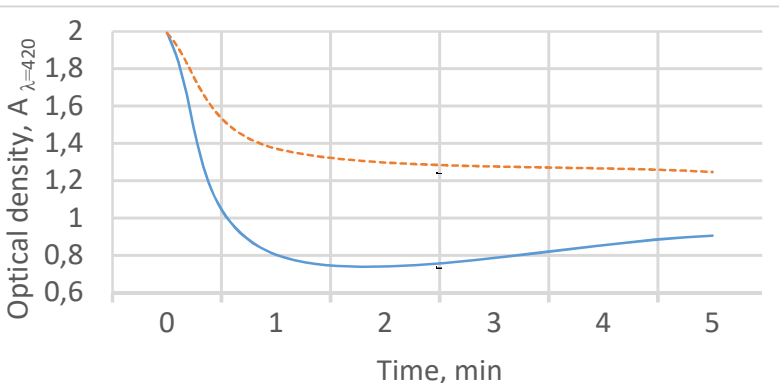

Italy bentonite

-- Germany bentonite

Figure 5. Dependence of the optical density on the mixing time

kinetics of the bentonite suspension is analyzed. Continuous mixing and stirring is performed with the help of a mechanical stirrer. The contact time ranged from $1-5 \mathrm{~min}$ at the stirring at intervals of $60 \mathrm{~min}$. The results of the investigation of the dependence between the optical density of white wine vinegar and the mixing duration with the Italian and Germany bentonite suspension are presented in Figure 5. It is noted that at a continuous and intensive mixing, an effective distribution of bentonite suspension particles throughout the volume of wine vinegar is ensured. Experience has shown that in the case of using Italian bentonite suspension it is not necessary to increase the mixing time beyond $1 \mathrm{~min}$, as this is sufficient to obtain a well-clarified preparation. In addition, when using German bentonite suspension, it is necessary to increase the mixing time up to $5 \mathrm{~min}$, because its gelling structure requires mixing for a longer period of time in order to come in contact with the impurities particles in the white wine vinegar.

\subsection{The influence of the centrifugation regime \\ on the separation of the bentonite suspension}

The process of clearing the vinegar of white wine also depends on the centrifugation regime. The duration of the centrifugation regime varies between 3-6 min, and the centrifugation speed of $3000 \mathrm{~min}^{-1}$. Figure 6 shows the results of the optical density dependence of white wine vinegar clarified with Italian and Germany bentonite suspension on the centrifugation time. Analyzing the obtained results, it is observed that the kinetic curves have two distinct phases. In the first phase ( $0-3 \mathrm{~min})$ the optical density of white wine vinegar decreases greatly. And in the second phase (3-6 min), it is observed that the optical density remains practically constant and changes nonessential over time. The results show that the process of clearing the white wine vinegar is dependent on the quality and the physicochemical characteristics of the bentonite suspension used. However, from the obtained experimental data it is observed that the clearing process is carried out sufficiently for $3 \mathrm{~min}$ for both types of bentonite. Increasing the centrifugation time does not fundamentally change the optical density value of the clarified vinegar. Thus the optimum

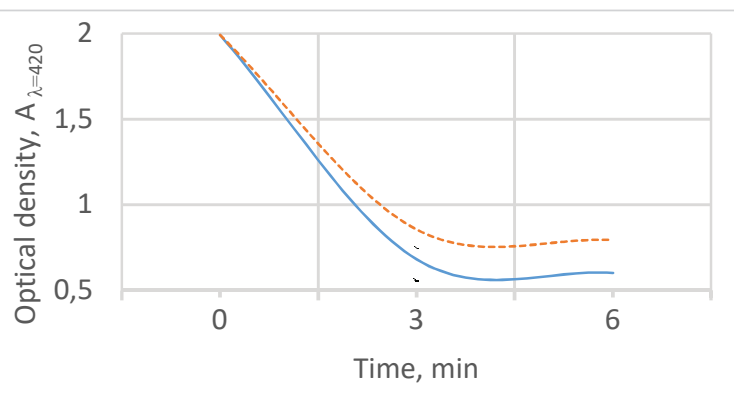

Italy bentonite -..-..-.- Germany bentonite

Figure 6. Dependence of the optical density of the duration of centrifugation

regime of centrifugation of white wine vinegar with bentonite suspension is: the centrifugation time $3 \mathrm{~min}$ and the centrifugation speed of $3000 \mathrm{~min}^{-1}$.

\subsection{The influence of bentonite dose on vinegar quality indices}

Determination of the physico-chemical parameters: $\mathrm{pH}$, total acidity, dry extract, ash was made using a quantity of bentonite which ranged from 1 to $3 \mathrm{~g} \cdot \mathrm{L}^{-1}$.

$p H$. It was determined how to change the $\mathrm{pH}$ value of wine vinegar depending on the amount of bentonite used. The experiment was performed on the basis of a set of four vinegar samples in which a quantity of bentonite was added which ranged from 1 to $3 \mathrm{~g} \cdot \mathrm{L}^{-1}$, the experimental data are shown in Figure 7 .

The suspension of Italian bentonite contributes to a $\mathrm{pH}$ increase of $1.60 \%$ and it is kept constant regardless of the quantity used. In the case of German bentonite suspension, is observed a pH increase of 0.32 and $1.28 \%$. Even if there is a tendency to increase the $\mathrm{pH}$ value, this is insignificant. Thus, it can be realized that the amount of bentonite suspension used for clearing white wine vinegar does not influence its quality.

Total acidity: Total acidity is a prime indicator that shows the completion of the vinegar acetic fermentation process. The content of acetic acid is that indicator on which international standards distinguish vinegar quality. Because the clarification process is carried out at the end of the acetic fermentation, the purpose of the clarifying substances is to flocculate and sediment the impurities formed, but it does not have to change the quality of the vinegar. Testing of Italian and German bentonite suspensions was performed by analyzing four white wine vinegar samples in which a suspension amount ranging from 1 to $3 \mathrm{~g} \cdot \mathrm{L}^{-1}$ was added.

Based on the experimental data shown in Figure 8 it can be argued that Italian bentonite suspension is suitable for vinegar clarification, as it does not change the total acidity value regardless of the quantity used. The suspension of German bentonite causes a $2 \%$ increase in total acidity when using 1 and $2 \mathrm{~g} \cdot \mathrm{L}^{-1}$ of bentonite.

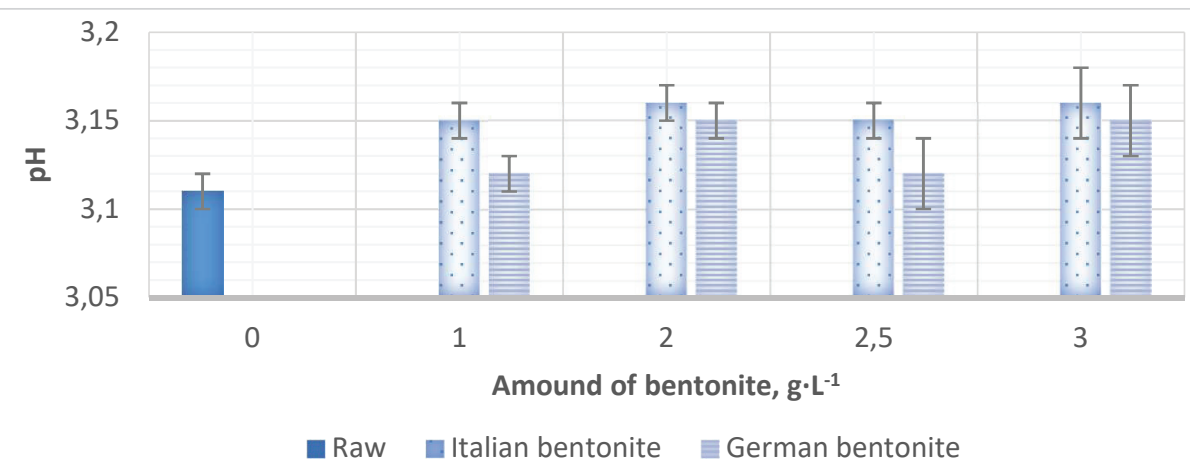

Figure 7. Dependence of the $\mathrm{pH}$ value of the wine vinegar on the used bentonite amount 


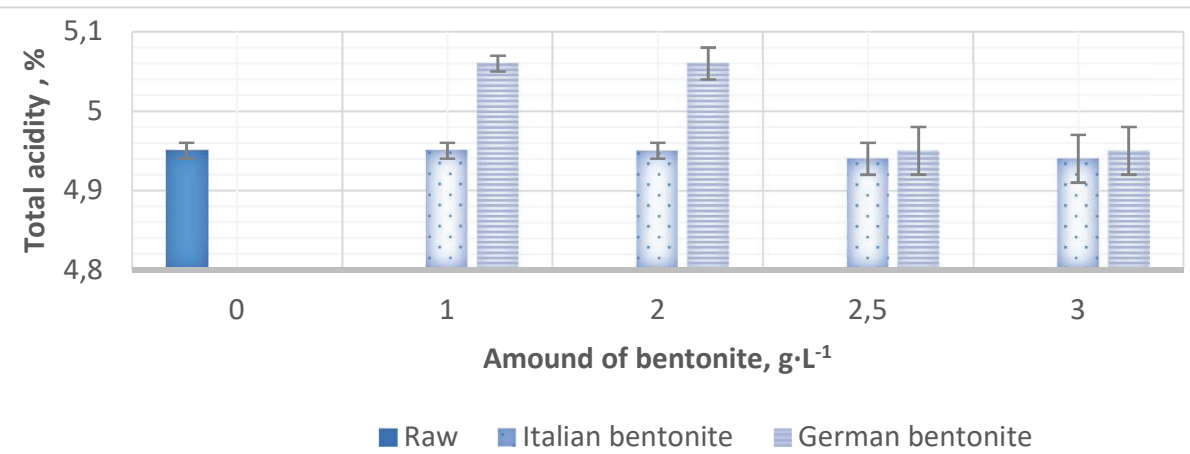

Figure 8. Dependence of the total acidity value of the wine vinegar on the used bentonite amount

As the dose of bentonite increases, total acidity stabilization is observed at the initial value of vinegar. The variation of these values may be a cause of the gelling structure of the German bentonite suspension which contributed to the erroneous data obtained.

Density: Density is a physicochemical characteristic of vinegar that does not have to undergo substantial changes. Thus, it was proposed to analyze the transformations supported by this parameter during the vinegar clearing process, depending on the amount of bentonite suspension used, which ranged from 1 to $3 \mathrm{~g} \cdot \mathrm{L}^{-1}$.

Analyzing the data presented in Figure 9, it is found that bentonite suspension has a tendency to increase the value of wine vinegar density. In the case of the use of Italian bentonite suspension, an increase in density is recorded but does not exceed the allowable values according to [16]. And when using the German bentonite suspension, with the increase in the amount of bentonite, there is an increase in density over the permissible limit value. Thus it can be concluded that in the process of wine vinegar clarification with bentonite to avoid increasing the density, the determined optimum quantity must be respected and the use of a larger quantity is not allowed.

Dry matter: The dry matter is a quality indicator that confirms whether fraud has occurred during the vinegar manufacturing process. It was investigated how to modify the ash content de- pending on the dose of bentonite used during the clearing process.

Based on the results shown in Figure 10, an increase in the dry matter quantity of white wine vinegar clarified with Italian and German bentonite is observed, this quantity is within the permissible limit $8.71-25 \mathrm{~g} \cdot \mathrm{L}^{-1}$. Thus it can be confirmed that the amount of bentonite administered does not influence the quality of the vinegar. Comparing the results obtained with the dry matter of $8.95 \mathrm{~g} \cdot \mathrm{L}^{-1}$ in the white wine vinegar obtained in another paper, we can confirm that the dry matter can be reduced by using another type of bentonite, which has a higher capacity of flocculation of proteins and impurities.

Ash content: Ash represents a quality indicator of white wine vinegar, for this reason the clarifying substances used for clarification should not increase its content. The purpose of the experiment was to determine how the ash content changes depending on the amount of bentonite suspension used.

According to the experimental results presented in Figure 11 it can be confirmed that the ash content decrease of white wine vinegar depends on the amount of bentonite suspension used. Italian bentonite suspension has the capacity to reduce ash content by 29.23 to $37.60 \%$. When using German bentonite suspension, it is observed that it has a lower capacity of 9.70 to $24.60 \%$ to reduce the ash content of white wine vinegar. It can be observed that

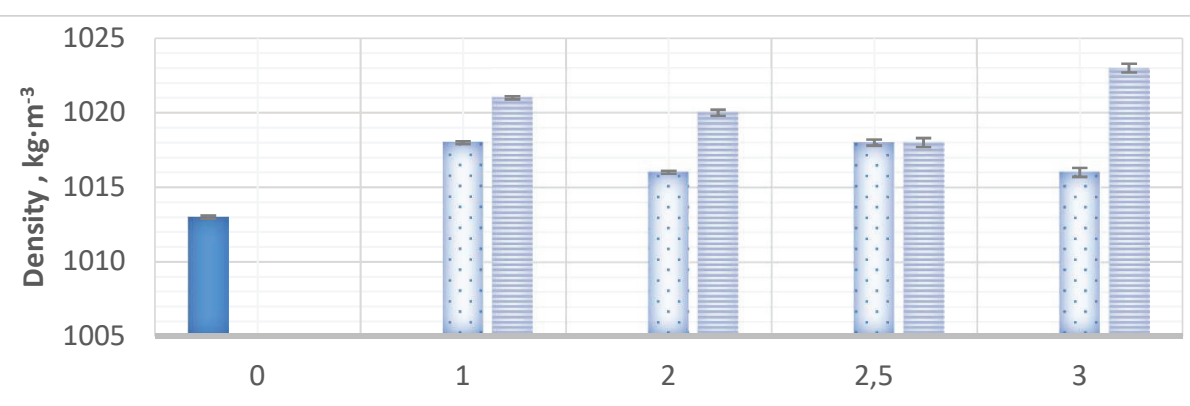

Amound of bentonite, $g \cdot L^{-1}$

Figure 9. Dependence of density of the clarified wine vinegar on the used bentonite amount

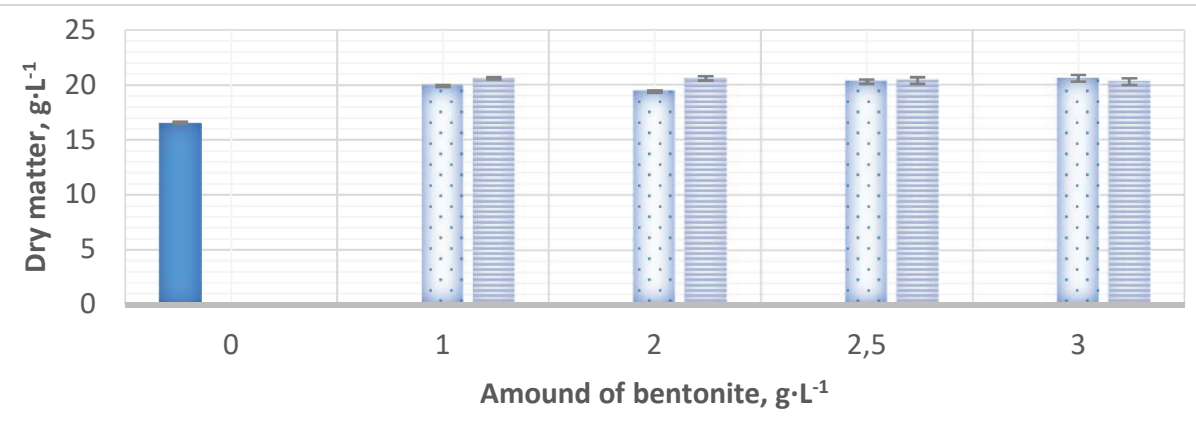

- Raw Italian bentonite Eerman bentonite

Figure 10. Dependence of dry matter of wine vinegar on the used bentonite amount 


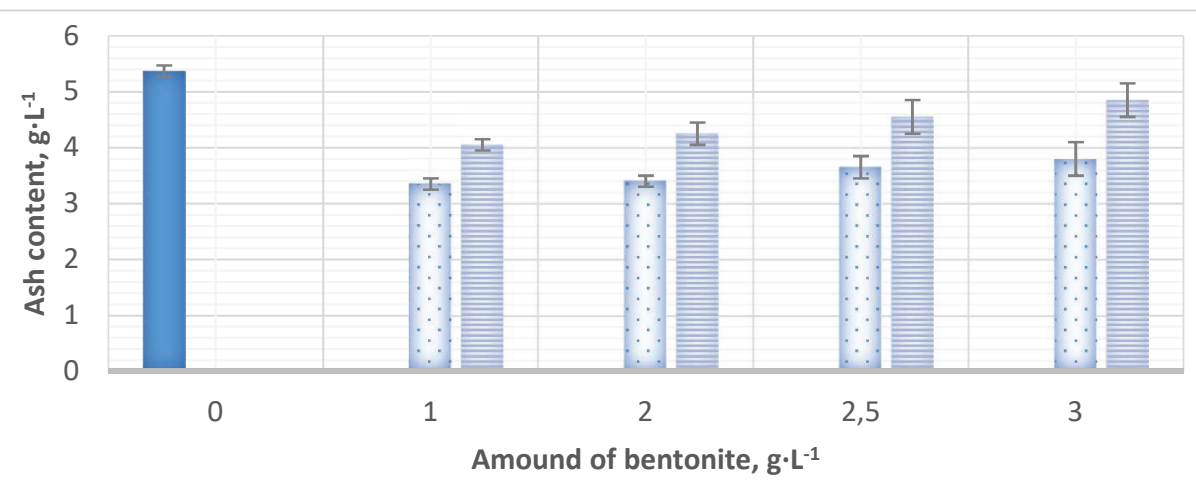

- Raw Italian bentonite $\equiv$ German bentonite

Figure 11. Dependence of the ash quantity of wine vinegar on the used bentonite amount

when using both types of bentonite the decrease in ash content is inversely proportional to the amount of suspension administered. This can be explained by the fact that a small dose of bentonite has the ability to flocculate and sediment all the impurities in white wine vinegar. And with increasing the dose of bentonite, small particles of bentonite that sediment harder remain in white wine vinegar. In order to avoid the presence of bentonite particles, it is recommended that the optimum amount of suspension to be used in the vinegar clarification process.

\subsection{Influence of the bentonite contact time}

\section{on white wine vinegar on quality parameters}

$p H$ : The degree of white wine vinegar clarity depends on the contact time of the product with the bentonite suspension. It is very important that the clarification time increase does not affect any vinegar quality parameter. The supported changes in vinegar $\mathrm{pH}$ were investigated following the clarification process with the Italian and
German bentonite suspension. Each type of bentonite was contacted with vinegar for a period of time ranging from 15 to $75 \mathrm{~min}$.

Analyzing the data presented in Figure 12, it is noticed that depending on the contact time of the product with the bentonite suspension produced by Italy, the $\mathrm{pH}$ value increases by $1.60 \%$ and remains constant over time. When using German bentonite suspension, the $\mathrm{pH}$ value increases from $1.26 \%$ to $1.60 \%$. It can be approved that in the case of increasing the time of the wine vinegar clarification process with the suspension of bentonite, the $\mathrm{pH}$ increases for the final product is non-essential.

Total Acidity: The change in the value of the total acidity of the wine vinegar was investigated depending on the contact duration with the bentonite suspension. The analysis of Italian and German bentonite suspensions was performed by analyzing four vinegar samples in which a suspension quantity of $3 \mathrm{~g} \cdot \mathrm{L}^{-1}$ was added, which was contacted with the product for a certain time, from 15 to $75 \mathrm{~min}$.

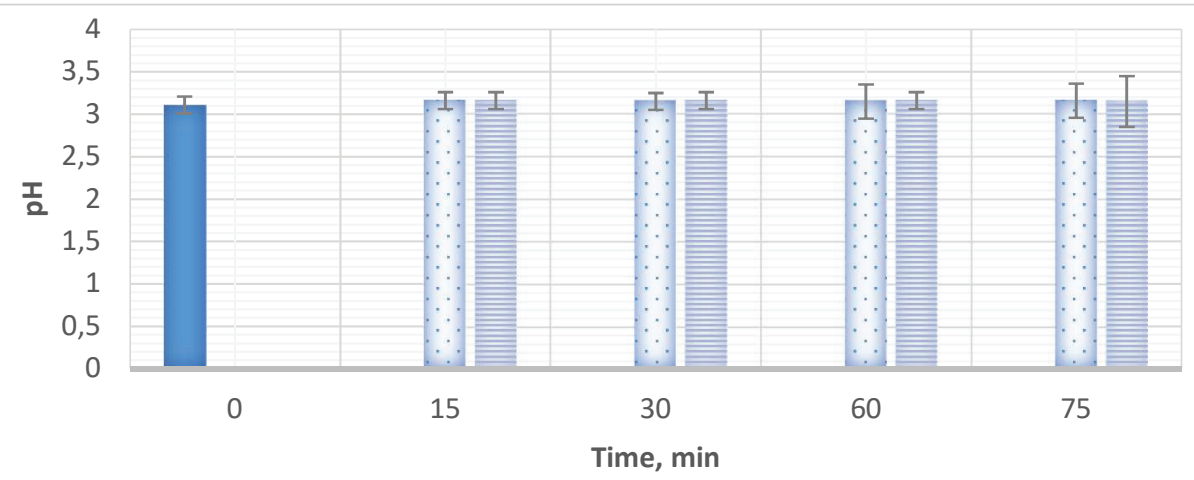

- Raw Italian bentonite E German bentonite

Figure 12. Dependence of the $\mathrm{pH}$ value of the wine vinegar on the contact duration with the bentonite suspension

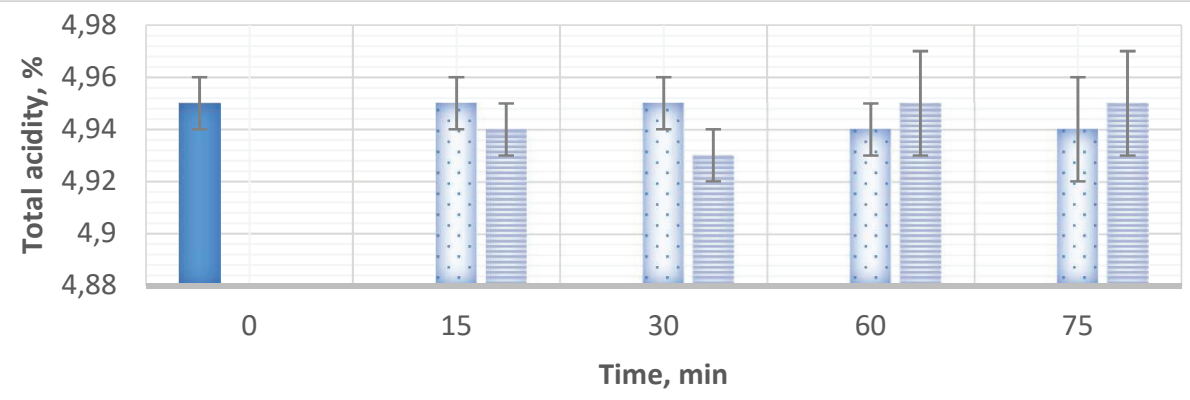

- Raw Italian bentonite $=$ German bentonite

Figure 13. Dependence of the value of the total acidity of the wine vinegar on the contact duration with the bentonite suspension 
According to the obtained experimental results shown in Figure 13 it can be argued that when using Italy's bentonite suspension, the value of acidity remains unchanged for a period of up to 30 min. With increasing contact time, a decrease in total acidity value is recorded. It shows that in the case of using the Italian bentonite suspension in the clearing process, the optimum time of 30 min must be respected. In the case of the use of the bentonite suspension produced by Germany, there is a very small decrease in total acidity after $15 \mathrm{~min}$, but the acidity value returns to the initial results of $4.95 \%$ for the other samples and remains constant over time. The deviation of the total acidity for the first sample can be considered an experimental error. Thus it can be argued that bentonite producer Germany does not alter the total acidity of wine vinegar regardless of the contact time.

Density: The influence of the contact duration of bentonite suspension on the value of wine vinegar density was analyzed. The experience was based on four samples that were subjected to the clearing process in a time interval that ranged from 15 to $75 \mathrm{~min}$.

According to the data shown in Figure 14, it is noted that the time-dependent bentonite suspension has the tendency to increase the wine vinegar density. Italian bentonite suspension has the capacity to increase the density of vinegar by $0.69 \%$, and the German one - by up to $0.49 \%$. But the variation of these values is within the permissible limit of $1013-1020 \mathrm{~kg} /$ $\mathrm{m}^{3}$, according to [17], thus it can be concluded that the contact time with the bentonite suspension does not influence the wine vinegar density.

Dry matter: An analysis of the modification of the dry substance content was performed depending on the contact time with the bentonite suspension. The research was carried out on a sample of
4 wine vinegar samples in which a quantity of $3 \mathrm{~g} \cdot \mathrm{L}^{-1}$ of bentonite was added and the clearing process lasted from 15 to $75 \mathrm{~min}$. The experimental data obtained are shown in Figure 15.

According to the obtained results, it is observed that clearing the vinegar with the Italian bentonite suspension in time dependence results in a reduction of the quantity of dry matter up to $8 \%$. And in the case of the use of German bentonite suspension, there is an increase of the dry matter from $19.40 \mathrm{~g} \cdot \mathrm{L}^{-1}$ to 20.90 $\mathrm{g} \cdot \mathrm{L}^{-1}$ and is directly proportional to the increase of the contact time. Thus, it can be concluded that the bentonite suspension in Italy has a more positive impact on the vinegar clearing process of white wine, as it does not contribute to the increase in the quantity of dry matter regardless of the contact time.

Ash content: The clarifying substances used should not alter the quality of wine vinegar regardless of the contact time. This experiment was carried out in order to determine how the ash content changes depending on the contact time with the bentonite suspension produced in Italy and Germany. The results were recorded on a sample of 4 vinegar samples in which an amount of $3 \mathrm{~g} \cdot \mathrm{L}^{-1}$ suspension of bentonite was administered and were left for a period of time ranging from 15 to $75 \mathrm{~min}$, the experimental data are shown in Figure 16.

It can be confirmed that the ash content in wine vinegar is reduced in percentage with a value ranging from 33.90 to $40.40 \%$ following the process of clearing with the bentonite suspension of the Italian and German producers. The values of the ash content change in a non-essential way from 15 to $75 \mathrm{~min}$. These results confirm that the contact time does not affect the quality of the product and it is sufficient that the cleaning process lasts $45 \mathrm{~min}$, according to the optimum preset time.

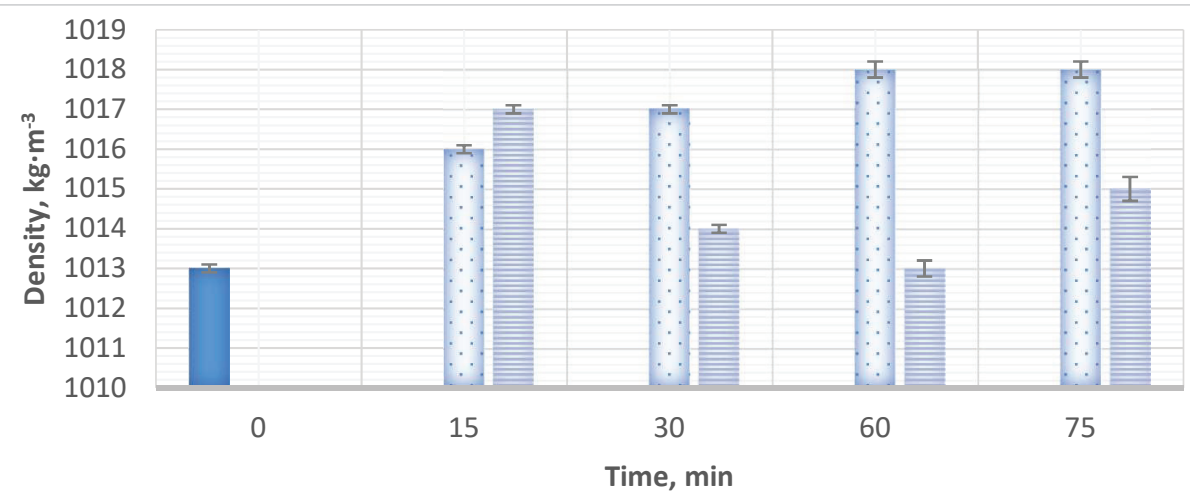

- Raw Italian bentonite $\equiv$ German bentonite

Figure 14. Dependence of the white wine vinegar density on the contact duration with bentonite

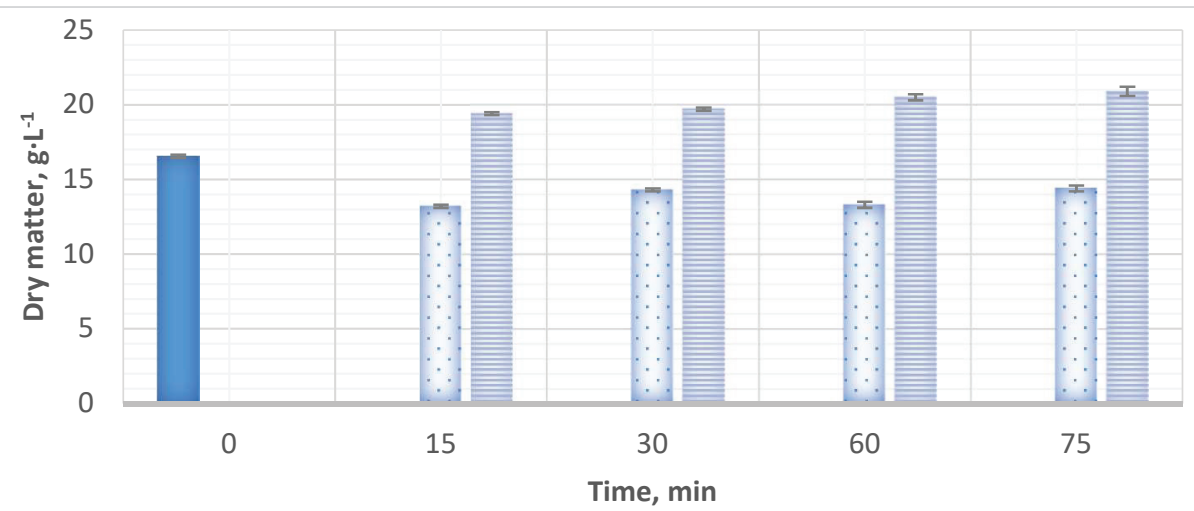

- Raw Italian bentonite $\equiv$ German bentonite

Figure 15. Content of dry matter depending on the contact time of white wine vinegar with bentonite suspension 


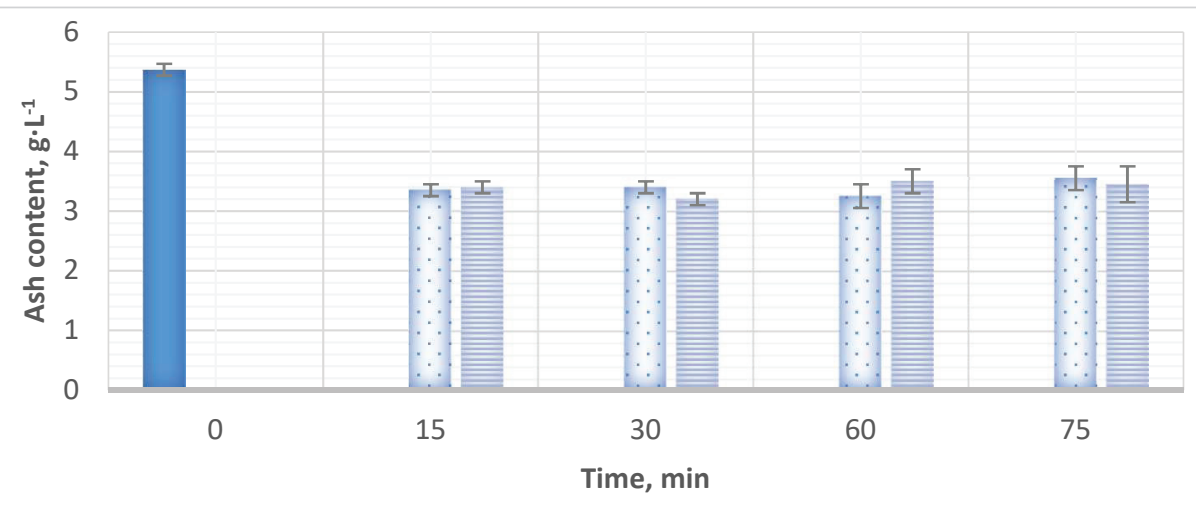

- Raw Italian bentonite EGerman bentonite

Figure 16. Dependence of the ash quantity of wine vinegar on the contact duration with the bentonite suspension

\section{Conclusions}

In the paper, physicochemical parameters of turbid and unstable white wine vinegar obtained after the acetic fermentation process. These parameters served as a benchmark for the next steps of the research.

The process of adsorbent clarification with bentonite from different manufacturers was investigated. It was found that the adsorption effect is largely determined by the interaction of bentonites with the protein substances in wine vinegar.

The optimum conditions for the adsorption process of the impurities from the white wine vinegar with the two types of bentonite used were established. Thus, for the bentonite of the Italian manufacturer, the optimal conditions for the clarification process are: dose of bentonite $-2.03 \mathrm{~g} \cdot \mathrm{L}^{-1}$, time $-45 \mathrm{~min}$, temperature $-20 \pm 1{ }^{\circ} \mathrm{C}$, stirring time $-1 \mathrm{~min}$, centrifugation time 3 min and spin speed of $300 \mathrm{~min}^{-1}$. And when using the German manufacturer's bentonite, the optimal parameters are: bentonite dose $-1.96 \mathrm{~g} \cdot \mathrm{L}^{-1}$, time $-45 \mathrm{~min}$, temperature $-20 \pm 1{ }^{\circ} \mathrm{C}$, stirring time $-5 \mathrm{~min}$, centrifugation time $-3 \mathrm{~min}$ and spin speed of $300 \mathrm{~min}^{-1}$.

Based on the research of the influence of bentonite on the clearing process carried out under laboratory conditions, it was found that the adsorption process does not affect the quality of the physicochemical parameters of vinegar from white wine. In addition, for clarification of wine vinegar from two types of bentonites, Italian is more suitable.

\section{REFERENCES}

1. Bourgeois, J. F., Barja, F. (2009). The history of vinegar and of its acetification systems. Archives des sciences, 62(2), 147-160.

2. Enache, M. (2013). Clarification of the wine with gelatin. [Electronic resource: https://ru.scribd.com/document/172388305/L04-LimpezireaVinului-Cu-Gelatina/ Access date 14.02.2020] (in Romanian)

3. US2043713A Patent: Wine and vinegar clarification process Lawrence, G., Sayweli, B., Calif., Patented June 9, 1936, Serial No. 759,047.

4. Moreno-Arribas, M. V., Polo, M. C. (2009). Wine Chemistry and Biochemistry. New York: Springer Science \& Business Media. -735 p. ISBN9780-387-74118-5, DOI 10.1007/978-0-387-74118-5.

5. Leske, P. A., Bruer, N. G. C., Capdeboscq, V. (1995). An evaluation of some characteristics of commercial bentonites. Wine Industry Journal, 10(1), 73-77.

6. GD n. 1403 of 09.12 .2008 «Vinegars and acetic acid for food use» published: 19.12.2008 Monitorul Oficial Nr. 226-229 art Nr:1422 (in Romanian)

7. Baize, D. (2000). Guide to soil analysis: choice, expression, presentation, interpretation. Paris: INRA. - 257 p. ISSN: 1150-3912, ISBN: 2-73800892-5. (in French)

8. Caillaud, J., Proust, D., Righi, D. (2006). Weathering sequences of rockforming minerals in a serpentinite: influence of microsystems on clay mineralogy. Clays and Clay Minerals, 54(1), 87-100. https://doi. org/10.1346/ccmn.2006.0540111

9. Amin, N. C., Andji, Y. Y. J., Ake, M., Yolou, S.F., Toure-Abba, A., Kra Gabrielle, (2009). Mineralogy and physico-chemistry of clay using for treatment of buruli ulcer in Cote d'Ivoire, Journal of Pharmaceutical and Biological Sciences, 10(1), 21-30. [Electronic resource: http://docplayer.fr/39661072Mineralogie-et-physicochimie-d-argiles-de-traitement-de-l-ulcere-deburuli-en-cote-d-ivoire.html/ Access date 16.03.2020] (in French)

10. Waanders, F. B., Ungerer, E., Fosso-Kankeu, E. (2015). Correlation between swelling index of bentonite clay and the strength of pellets. 7 th
International Conference on latest Trends in Engineering and Technology (ICLTET'2015), At: Irene Pretoria South Africa. Volume: 24-27. ISBN97893-84422-58-2.

11. Konan, K. L., Soro, J. Y., Andji, S., Oyetola, S., Kra, G. (2010). Comparative Study of Dihydroxylation/Amorphization in Two Kaolins with Different Crystallinity. Journal de la Société Ouest-Africaine de Chimie, 030, 29-39. [Electronic resource: http://www.soachim.org/files/volume_30/4-\%20 Konan\%20K.\%20L\%C3\%A9on\%20et\%20al,\%2029\%20-\%2040,\%20 Vol\%20030,\%202010.pdf Access date 16.03.2020] (in French)

12. Kobayashi, T. (2004). Recent Progress of Biochemical And Biomedical Engineering In Japan II. Berlin Heidelberg: Springer-Verlag. https://doi. org/10.1007/b14093, ISBN978-3-540-20419-0

13. Polo, M. C., Llaguno, C. (1991). Wine Vinegar. Madrid: Espagne. -238p. ISBN978-84-00-07205-6 (in Spanish)

14. RESOLUTION OENO 57-2000 Wine vinegars. [Electronic resource: https://studylib.es/doc/8194216/resoluci\%C3\%B3n-oeno-57-2000-vi.vinagres-de-vino / Access date 16.03.2020] (in Spanish)

15. Bourdreux, S. (2003). Acids in drinks. Oualitative and quantitative aspects. [Electronic resource: https://docplayer.fr/11355714-Les-acidesdans-les-boissons-aspects-qualitatifs-et-quantitatifs.html/ Access date 14.02.2020] (in French)

16. De la Haba, M. J., Arias, M., Ramírez, P., López, M-I., Sánchez, M-T. (2014). Characterizing and Authenticating Montilla-Moriles PDO Vinegars Using Near Infrared Reflectance Spectroscopy (NIRS) Technology. Sensors, 14(2), 3528-3542. https://doi.org/10.3390/s140203528

17. Muhlack, R., Nordestgaard, S., Waters, E. J., O’Neill, B. K, Lim, A., Colby, C. B., (2006). In-line dosing for bentonite fining of wine or juice: Contact time, clarification, product recovery and sensory effects. Australian Journal of Grape and Wine Research, 12(3), 221-234. https://doi. org/10.1111/j.1755-0238.2006.tb00062.x 


\section{AUTHOR INFORMATION}

Alina Boistean - candidate of technical sciences, docent, Department of Food and Nutrition, Technical University of Moldova. 168, Stefan cel Mare Bd., Chisinau, Republic of Moldova. Tel.: +373-69-081-217, e-mail: alina.boistean@toap.utm.md ORCID: https://orcid.org/0000-0002-5374-5853

*corresponding author

Aurica Chirsanova - doctor of microbiology sciences, Head of Department of Food and Nutrition, Technical University of Moldova. 168, Stefan cel Mare Bd., Chisinau, Republic of Moldova. Tel.: +373-79-770-751, e-mail: aurica.chirsanova@toap.utm.md

ORCID: https://orcid.org/0000-0002-1172-9900

Jorj Ciumac - doctor of technical sciences, professor in the Francophone Branch «Tehnologies Alimentaires», Technical University of Moldova. 168, Stefan cel Mare Bd., Chisinau, Republic of Moldova. Tel.: +373-69-935-767, e-mail: jorj.ciumac@toap.utm.md ORCID: https://orcid.org/0000-0002-4258-752X

Boris Gaina - doctor of technical sciences, academician of Academy of Sciences of Moldova, leader of the Life Sciences Department, Academy of Sciences of Moldova, 1, Stefan cel Mare Bd., Chisinau, Republic of Moldova. Tel.: +373-69-870-877, e-mail: boris.gaina@ffta.utm.md ORCID: https://orcid.org/0000-0002-3536-1477

All authors bear responsibility for the work and presented data.

All authors made an equal contribution to the work.

The authors were equally involved in writing the manuscript and bear the equal responsibility for plagiarism.

The authors declare no conflict of interest.

Received 17.02.2020 Accepted in revised 16.03.2020 Accepted for publication 23.03.2020 